\title{
deuKariyeriM: Üniversiteler İçin Bir Kariyer Yönetim Sistemi
}

\author{
Muhammet Damar ${ }^{1}$, Yaşar Dereli $^{1}$, Zafer Dicle $^{1}$ \\ ${ }^{1}$ Dokuz Eylül Üniversitesi Bilgi İșlem Daire Başkanlığı, İzmir, Türkiye \\ damarmuhammet@gmail.com, yasar.dereli@deu.edu.tr, zafer@deu.edu.tr \\ (Geliş/Received: 09.01.2015; Kabul/Accepted: 03.04.2015) \\ DOI: $10.17671 / \mathrm{btd} .50106$
}

\begin{abstract}
Özet- Üniversitelerin en önemli amaçlarından birisi nitelikli insan gücü yetiștirmektir. Bu noktada Dokuz Eylül Üniversitesi mezunları ve öğrenim görmekte olan öğrencileri için bir kariyer yönetim sistemi gerçekleştirilmiş̧ir. Gerçekleştirilen uygulama kariyer planlama koordinatörlüğü ve fakülte birim sekreterlerinin yaşamış oldukları iletişim problemine çözüm bulmaktadır. Proje web uygulaması ve mobil uygulama olmak üzere iki farklı modülden oluşmaktadır. Çalışmada üniversiteler için geliştirilebilecek idealize edilmiş bir kariyer sistemi gerek literatür taraması gerekse var olan ihtiyaçlar ve süreçler doğrultusunda kavramsal olarak ele alınmıştır. Dokuz Eylül Üniversitesi mezunlarının ve öğrencilerinin sanayiden gelen iş imkânları, etkinlik ve eğitim haberleri gibi haberler konusunda kolay bir şekilde haberdar edilmesi uygulama içinde hedeflenmiş̧ir. Mezunların ve öğrenim gören öğrencilerin kariyer süreçleri sistem yaklaşımıyla ele alınmıştır. Gerçekleştirilen mobil uygulama Android cihazlarda kullanılabilmektedir. Hali hazırda Dokuz Eylül Üniversitesi Öğrencileri ve Mezunları tarafından "deuKariyeriM" isimli mobil uygulama Google Play Store üzerinden ücretsiz bir şekilde indirilebilmektedir. Aynı zamanda web arayüzü sayesinde, yetkiye göre, ilgili birimlere, öğrenciler ve mezunlar ile iletişim imkanı sunar. Çalışmanın diğer üniversitelere, mezun ve öğrenimi süren öğrencilerin kariyer süreçlerinde örnek teşkil edeceği ve literatür çerçevesinde üniversite kariyer yönetim süreçlerine katkı sağlayacağı beklenmektedir.
\end{abstract}

Anahtar Kelimeler - kariyer yönetim sistemi, mezun bilgi sistemi, öğrenci haberleşme, duyuru sistemi

\section{deuKariyeriM: A Career Management System for Universities}

\begin{abstract}
One of the most important goals of the university is to train qualified manpower. At this point, a career management system software for Dokuz Eylul University students and graduates has been developed. This software application creates a solution for the communication problems experienced by the career planning coordinator and faculty secretaries. Software project consists of a web application and a mobile application. In this study, according to the requirement analysis and business process flow, an idealized career management system has been conceptually investigated throughout the literature. Developing an easy way to inform Dokuz Eylul University graduates and students about the business opportunities from industry, events and education news is one of the aims of the application. Mobile application of this study is working on devices with android operating systems. The mobile application is named as "deuKariyeriM" and it can be downloaded price free from Google Play Store. Meanwhile, related administrative units can communicate with the students and graduates through the web interface. This study offers a sample model for career management of the students and graduates to the other universities, through literature investigation, therefore it will contribute to the career management process.
\end{abstract}

Keywords - Career Management System, Alumni Information System, Student Communication, Announcement System

\section{GIRIŞ (INTRODUCTION)}

İş dünyasında yaşanan hılı değişimler ve bilgi teknolojilerinin geldiği nokta kamu sektöründe bazı değişiklikleri gerekli kılmıştır. Üniversitelerin önemli amaçlarından birisi toplumun ihtiyaç duyduğu nitelikli insan gücünü yetiştirmektir[1,2,4]. $\mathrm{Bu}$ açıdan bakıldığında, üniversitelerde kariyer planlama faaliyetlerini yürüten ilgili koordinatörlük ve birimlere önemli sorumluluklar düşmektedir.

Küresel rekabet, üniversiteler için önemli bir baskı unsuru haline gelmiştir. Bu baskı üniversiteleri amaç, yapı, süreç ve çıktılar açısından yeniden gözden geçirmeye zorlamakta ve üniversitelerin nasıl yönetileceğine ilişkin yeni açllımlar getirmektedir[10]. 
Günümüzde uluslararası kariyer rehberliğinin önemi artmaktadır. Avrupa Birliğgi, Dünya Bankası, Ekonomik İşbirliği ve Kalkınma Örgütü tarafından 37 ülkede çeşitli kariyer rehberliği politikaları finanse edilmektedir[17].

İlk kuruldukları dönemlerde bulundukları bölgenin din, dil ve kültür merkezleri olan üniversiteler, değişen dünya şartları ile birlikte bir meslek edindirme kurumu olarak algılanmaya başlanmıştır. $\mathrm{Bu}$ hızlı dönüşüm mezun olmaları, toplumun gereksinim ve beklentilerine hizmet etmektedir. Aynı zamanda öğrencilerin beklentilerinin karşılanması durumunda, üniversiteden alacakları doyum düzeylerinin yükseleceği öngörülmektedir[11].

Üniversite öğrencileri, öğrenim görmeye başladıkları ilk yıllarda daha çok barınma, uyum, yalnızlık gibi sorunlar ile karşılaşmaktadırlar. Öğrenciliklerinin ilerleyen

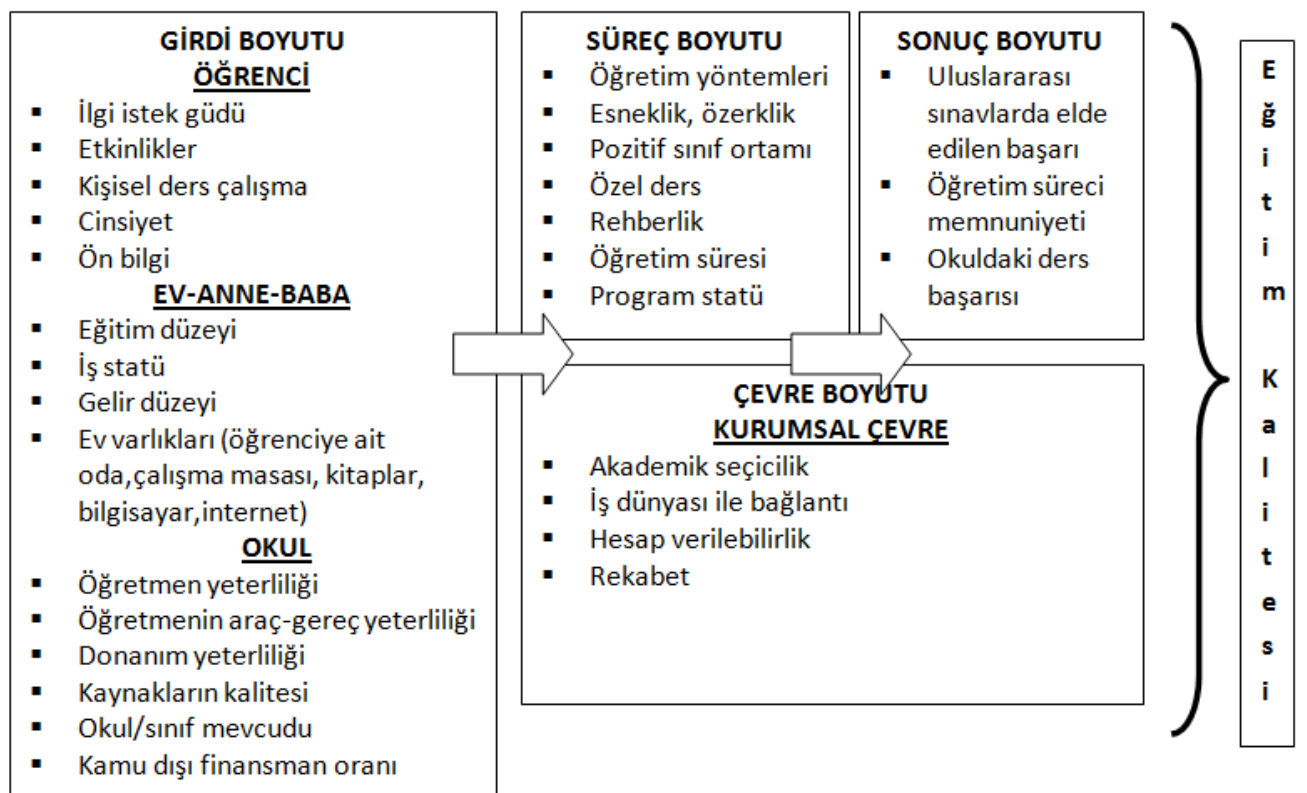

Şekil 1. Pisa 2006 Verilerine Göre Türkiye’de Eğitimin Kalitesini Belirleyen Temel Faktörler[22] (Determining the Quality of Education in Turkey in Pisa in 2006 by Data Key Factors [22])

üniversitelerin vizyon ve misyonlarında birtakım değişiklikler yapılmasına zemin hazırlamıştır[1].

Mezun ve öğrenimi süren öğrenciler üniversitelerin bir ürünüdür. Ait oldukları sosyal çevre ve istihdam edildikleri sektör itibariyle bir itibar göstergesidir. Bu öğrencilerin kariyer süreçlerini etkinleştirmek, öğrenciler ile iletişim halinde bulunmak günümüzde önemli hale gelmiştir. $\mathrm{Bu}$ noktada, mezun ve öğrenimine devam etmekte olan öğrencilerin kariyer süreçlerini, bilgi sistemleri vasıtasıyla kolaylaştıran kariyer yönetim sistemi, Dokuz Eylül Üniversitesi(DEÜ)'nde deüKariyeriM adıyla gerçekleştirilmiştir.

Gerçekleştirilen uygulama, kariyer planlama koordinatörlüğü, fakülte, enstitü ve yüksekokul sekreterlikleri, öğrenciler, mezunlar, sanayiden gelen iş gücü talepleri, Dokuz Eylül Bilgi Sistemi(Debis), DEÜ öğrenci ve personel sistemi gibi birçok payda ihtiyaçlar doğrultusunda bir araya getirilerek oluşturulmuştur.

\section{LITERATÜR (LITERATURE)}

Yükseköğretim, bir basit girdi-çıktı analiziyle açıklanamayan, öğrencinin öğrenme ve gelişmesini sağlayan bir süreçtir. Öğrencilerin beklentilerine ve amaçlarını uygun kaliteli bir eğitim sürecinden geçerek yıllarında, sınav kaygısı, gelecek kaygısı, öğretim üyeleri ve sınıf arkadaşlarıyla ilişkiler, ders içeriğinin zorluğu, akademik problemler gibi çeşitli durumlar ile başa çıkmaları gerekmektedir[13]. Karataş ve arkadaşlarına göre[12], son yıllarda, üniversite öğrencilerinin psikolojik danışma gereksinimleri tüm dünyada olduğu gibi Türkiye'de de büyük ilgi görmeye başlamıştır. Buna rağmen, üniversite öğrencilerinin gereksinim ve sorun alanlarının sıklığı ve ciddiyeti konusunda sınırlı sayıda çalışma bulunmaktadır.

Türkiye'de üniversite öğrencilerinin yaşadıkları sorunları inceleyen araştırmalar, üniversite öğrencilerinin uyum sorunları, akademik sorunlar, iletişim sorunları, iş bulma ve gelecek kaygısı sorunları, ekonomik sorunlar, stres, kararsızlık, kaygı, depresyon gibi sorunları yaşadıklarını gözlemiştir[18]. Eğitim süreci, sadece sınıftaki akademik öğretimle sınırlı olmayan bunun dışında sınıf dışı öğrenciöğretim elemanı ilişkilerini, eğitim programını ve öğretim elemanının akademik danışmanlığını ve rehberliğini de içeren bir süreçtir[10]. Dünya'nın sayılı üniversiteleri, mezun öğrencileri ile etkileşim halinde bulunmayı kurum içi politika haline getirmiş ve bu noktada beş yıllık stratejik eylem planları oluşturmuşlardır[14,15,16].

Amerika Birleşik Devlerinde mezunlar ile ilgili çalışmalar yaygındır. Mezunlara halkla ilişkiler ve pazarlama yaklaşımıyla bakılmaktadır[26]. Bunun nedeni olarak 
mezun olan öğrencilerin üniversiteleri ile iletişim içinde kalmaları, üniversitelerine bağışlarda bulunmaları, mezun dernekleri kurmaları gösterilebilir. $\mathrm{Bu}$ durum aynı zamanda mezunlar ile iletişimin üniversiteler için maddi bir katkı sağlayabileceği sonucuna ulaştırabilir.

Güler ve arkadaşının yaptığı çalışmada geleceğe dair işsiz kalma endişesi taşımama ve iyi bir kariyer beklentisi içinde olmanın öğrencilerin yaşam memnuniyetini olumlu etkilediği görülmektedir[19]. Ülkemizde üniversitelerin eğitim ve öğretim olanakları, iletişim, bilişim ve ulaşım imkânları, veri toplama, işleme ve bilgi üretme olanak ve kapasiteleri gibi birçok imkân açısından birbirleriyle farklılık gösterdiği görülmektedir. Bu durum, öğrencilerin üniversiteyle ve kendi gelecekleriyle ilgili beklentilerinde farklılıklara yol açabilmektedir[21].

Kozak ve arkadaşına göre, öğrencilik döneminden itibaren kariyer planlamaya başlamak, mezuniyet sonrasında kolay iş bulma, çalışılacak alanla ilgili yetenekleri geliştirme ve profesyonel yaşama kolaylıkla uyum sağlama açısından son derece önemlidir[17]. Kozak ve arkadaşının gerçekleştirdiği Eskişehir Üniversitesi mezun öğrencilerin kariyer algısı çalışması sonucunda, mezunların, kariyer kararlarında yeterli düzeyde yönlendirme yapılmadığı, kariyer kararlarını maddi kaygılar doğrultusunda ve geleneksel kalıplara göre verdikleri, mezunların kariyer siteleri üzerinden bilgilendikleri görülmektedir. Değirmencioğlu çalışmasında, üniversite öğrenimine hak kazanan ve üniversitelerden mezun olan bireylerin iş arama ve iş bulma süreçleri üzerine, bulunan işlerin ve ulaştıkları olanakların neler olduğuna ilișkin araștırmaların az olduğunu vurgulamaktadır[25].

Yapılan literatür çalışmasının sonucu, üniversitelerdeki kariyer yönetim süreçlerinin önemini ortaya koymaktadır. Çalışma, üniversite birimleri, mezunlar ve öğrenim gören öğrencilerin kariyer süreçlerini sistematik bir yaklaşım ile ele alarak ihtiyaçlar doğrultusunda uygulama ortaya koymuştur. Literatür incelendiğinde gerçekleştirilen bu çalışmanın üniversite kariyer yönetimi açısından öncü çalışmalardan olduğu görülmektedir.

\section{KARIYYER, KARIYYER PLANLAMA, KARIYYER YÖNETIMI VE ÜNİVERSITTELER (CAREER, CAREER PLANNING, CAREER MANAGEMENT AND UNIVERSITIS)}

Yükseköğretim kurumları ülkelerin kalkınması ve gelişmesi için gerekli olan bilginin üretildiği ve insan kaynaklarının yetiştirildiği kurumlardır[27]. Bu bağlamda kariyer hizmetleri gün geçtikçe üniversiteler için kütüphane, laboratuar vb. hizmetler gibi zorunlu hizmetler haline gelmektedir. Bu noktada kariyer, kariyer planlaması ve kariyer yönetimi kavramlarını aşağıdaki şekilde açıklamak gerekir:

- Kariyer kavramı, bireyin çalışma yaşamı boyunca herhangi bir iş alanında ilerlemesi, deneyim ve beceri kazanmasıdır. Günlük yaşamda kariyer, ilerlemek, meslek, iş yaşamı, başarı, bireyin iş yaşamı boyunca üstlendiği roller ve bu roller ile ilgili deneyimler anlamlarında kullanılmaktadır[23].

- Kariyer planlaması, bir iş görenin sahip olduğu bilgi, yetenek, beceri ve güdülerinin geliştirilmesiyle, çalışmakta olduğu örgüt içindeki ilerleyişinin ya da yükselmesinin planlanmasıdır[24].

- Kariyer yönetimi, işe yerleştirme, potansiyel değerleme, danışmanlık ve eğitim gibi faaliyetleri içine alan ve bu faaliyetler aracılığıyla bireyin ilgi ve yeteneklerinin örgütsel firsatlar ile bütünleştirilmesi, istenilen diğer örgütsel sonuçların başarılması için tasarlanan faaliyetler bütünüdür[23].

İş hayatında iyi noktalarda bulunan mezunlar üniversiteler için bir prestij ve bir nüfus oluşturabilir. Köklü ve büyük üniversitelerimiz bu etkiden oluşturdukları vakıflar aracılığıyla faydalanmaktadır [8,28,29].

Üniversitelerin fonksiyonlarından biri olan nitelikli insan yetiştirme noktasında, nitelik ile üniversitenin prestiji doğru orantılıdır. Kariyer yönetimi genellikle işletmelerde insan kaynakları departmanı tarafından yürütülmektedir. Öğrenci odaklı düşündüğümüzde, üniversitelerde bu tür hizmetler kariyer planlama koordinatörlükleri ile mezun ofisleri tarafından gerçekleştirilmektedir.

\section{4. ÜNIVERSITE KARIYER PLANLAMA KOORDINATÖRLÜKLERİ VE MEZUN ILETISSIM OFISLERI (UNIVERSITY CAREER PLANNING COORDINATORSHIP AND ALUMNI CONTACT OFFICES)}

Çağdaş bir toplumda; bireylerin meslek seçimleri, yaşamlarındaki önemli bir noktadır. Bireyin uygun mesleği seçmesi, kendine ve topluma daha faydalı olabilmesi için gereklidir. Meslek seçim kararı, insanın yaşamı boyunca vereceği en önemli kararlardan biridir[3]. Kariyer süreçlerinde doğru kararı veren birey, hem kendi iç dünyasında hem de iş dünyasında daha başarılı olacak ve bu şekilde ait olduğu topluma daha faydalı olabilecektir. Üniversitelerin kariyer süreçleri ile ilgilenen kariyer planlama koordinatörlük ve birimleri ile mezun iletişim ofislerine, bu noktada önemli sorumluluklar düşmektedir.

Örneğin, Sabancı Üniversitesi, "Mezun Ofisi Dünya'nın neresinde olursanız olun Sabancı Üniversitesi ile iletişim kurmak için mezun ofisi burada" sloganını sitesinde kullanmaktadır[5].

Bir başka üniversitemiz, Boğaziçi Üniversitesinin mezun ofisi[6] ve kariyer merkezi[7] internet sayfaları üzerinden yapılan incelemede dikkat çeken başlıklar: 
- Mezun buluşmaları, mezunlardan haberler, mezun bu card,

- teknoloji transfer ofisi, ileri teknolojiler arge merkezi birimlerin mezunlara üniversite sanayi işbirliği projelerinin duyurulması,

- mezunlar için haberler, konser film vb. etkinlik duyurular1,

- mezun sertifika programları ve mezunların eğitim süreçlerini etkinleştirici eğitimler,

- öğrenim gören öğrenciler için öğrenci girişi,

- firma ilanlarının kolayca girilmesi için işveren girişleri,

- öğrenciler için faydalı bilgiler,

- okumakta olan öğrenciler için firmaların eğitim ve seminer duyuruları,

- Boğaziçi Üniversitesi Vakfi etkinlikleri, burslar, ödül haberleri, üniversite projelerine destek ve bağ1ş haberleri,

şeklinde sıralanabilir.

$\mathrm{Bu}$ iki üniversitenin kariyer süreçlerinden sorumlu birimlerinin ilgili web sayfaları üzerinde yapılan inceleme sonucunda; öğrencilerinin öğrenim gördükleri süreçte eğitim kalitelerini artırıcı faaliyetlerde bulunmalarının yanı sıra, eğitim sonrasında, okudukları üniversite kimliğini korumaya çalıştıkları ve onları üniversitenin bir parçası haline getirdikleri belirlenmiştir. Örneğin Boğaziçi Üniversitesi Mezun Ofisinin burs imkânları ve çeşitli yatırımlar konusunda oluşturulan vakıf aracılığıyla eski öğrencilerinden faydalandığı görülmektedir[8]. Aynı durum Dünya'nın sayılı üniversitelerinden birisi olan Harward Üniversitesinde "Bir ömür boyu bağlantı, akademik araştırma ve hizmete bağlılık" sloganıyla kurulmuş platform üzerinden, facebook, twiter ve linkedin gibi sosyal medya araçları, etkin bir şekilde kullanılarak gerçekleştirilmektedir[9]. Harward mezun sitesinin sağladığı belli başlı hizmetler:

- Mezun Arama Dizini: Online olarak mezun arama imkanı sağlamaktadır.

- Mezun Profili: Gerek Harvard Üniversitesinin mezunlar ile iletişimi gerekse diğer mezunların birbiriyle iletişimi için güncel iletişim bilgisi sağlar.

- Dizin ve E-posta Yönlendirme Hizmetleri: Harvard üniversitesi üzerinden e-posta hizmeti sağlar.

- Mezunlar Notlar: Mezunların anı, mesaj ve düşüncelerini paylaşma imkânı sağlar

- Tartışma Grupları: Mezunlar için bir tartışma ortamı ve etkileşim imkânı sağlar.

- Crimson Pusula: Crimson Pusula danışmanları okumakta olan öğrencilere rehberlik sağlayan gönüllülük esaslı bir kariyer danışmanlık hizmetidir.

- Mezun Eğitim: Mezunların kariyer gelişim süreçlerinde, kampus içi eğitim, ülke içinde ve dünya genelinde kariyer gelişim haberleri ve bilgileri sunan bir hizmettir.
- Harvard Mezunlar Dünya MasterCard: Harvard mezunları için özel olarak oluşturulmuş ve geliri ögrencilere mali yardım olarak dönen bir karttır,

şeklinde sıralanabilir

\section{KARIYYER YÖNETIM SISTEMI AMAÇ VE KAPSAMI (CAREER MANAGEMENT SYSTEM OBJECTIVES AND SCOPE)}

Günümüzde teknolojik gelişmelerine bağlı olarak kariyer planlama süreçlerinde önemli kolaylıklar yaşanmaktadır. Örneğin internet ve burada yapılanan kariyer siteleri, kurumların ve bireylerin kariyer süreçlerinde kullanılmaktadır[17]. $\mathrm{Bu}$ noktada geliştirilen deuKariyeriM (Dokuz Eylül Üniversitesi Kariyer Yönetim Sistemi) uygulaması, sistem yaklaşımı ile ihtiyaçlar ve yapılan analizler doğrultusunda projelendirilmiştir. Projenin amacı, kapsamı, teknolojisi, projeden sorumlu birimler ve etki alanı aşağıdaki şekilde siralanabilir:

- Kariyer yönetim sisteminin amac1: Öğrenimi devam eden ve mezun öğrencilerin etkin bir şekilde kariyer hizmetlerinden faydalanmasını sağlamaktır. $\mathrm{Bu}$ noktada sistem yaklaşımıyla süreçler oluşturulmuş ve süreçler doğrultusunda kurum içi duyuru, etkinlik, staj, burs, iș ilanları vb. konularda görevli birimlerin etkileşimi için bir sistem oluşturulmuştur.

- Kariyer yönetim sisteminin kapsamı: Süreçte mezunlar için mezun olmadan önce doldurulacak formdan, kurum içi etkinlik haberlerine kadar birçok süreç düşünülüp tasarlanmış bu süreç DEÜ kariyer yönetim süreçleri adıyla inşa edilmiştir.

- Çalışmada kullanılan yazılım teknolojiler; PHP programlama dili, oracle veri tabanı, android işletim sistemi, web servis, java programlama (eclips ortamı) dili şeklindedir.

- Sorumlu birimler; kariyer planlama koordinatörlüğü, fakülte, enstitü ve yüksekokul sekreterlikleri, bilgi işlem daire başkanlığı ve öğrenci işleri daire başkanlığı şeklindedir.

- Mezun ve öğrenim gören öğrenciler; sistemin ulaşmayı hedeflediği gruptur. $\mathrm{Bu}$ grup iş imkânları, staj imkânları, burs imkânları, çeşitli etkinlikler ve aktiviteler konusunda, mobil uygulama, debis sistemi ve kariyer planlama koordinatörlüğü internet sayfası vasitalarıyla bilgilendirilmektir.

\section{GERÇEKLEȘTİRIMLER (IMPLEMENTATIONS)}

Proje web uygulaması ve mobil uygulama olmak üzere iki farklı uygulamadan oluşmaktadır. Proje web uygulamasında Dokuz Eylül Üniversitesi Bilgi Sistemi (Debis), personel işleri ve öğrenci işleri otomasyonu ile entegre çalışabilen, öğrenci ile etkileşen, personelin 
yetkilendirebildiği bir modülden oluşmuştur. Süreçler aşağıdaki konu başlıklarıyla açıklanabilir.

\subsection{DEBIS Sistemi (DEBIS System)}

Debis, Dokuz Eylül Üniversite yazılım projelerinin web tarafını oluşturan, kullanıcıların yetkileri ölçüsünde erişime sahip oldukları bilgi sistemidir. Debis, kariyer yönetim sistemimiz için çatı işlevi görmektedir. Şekil 2 üzerinde ana ekran görünümü gösterilmiştir. Diğer üniversitelerde, örneğin; orbis[30], sabis[31] veya obs[32] gibi kullanılan sistemler ile benzerlik göstermektedir.

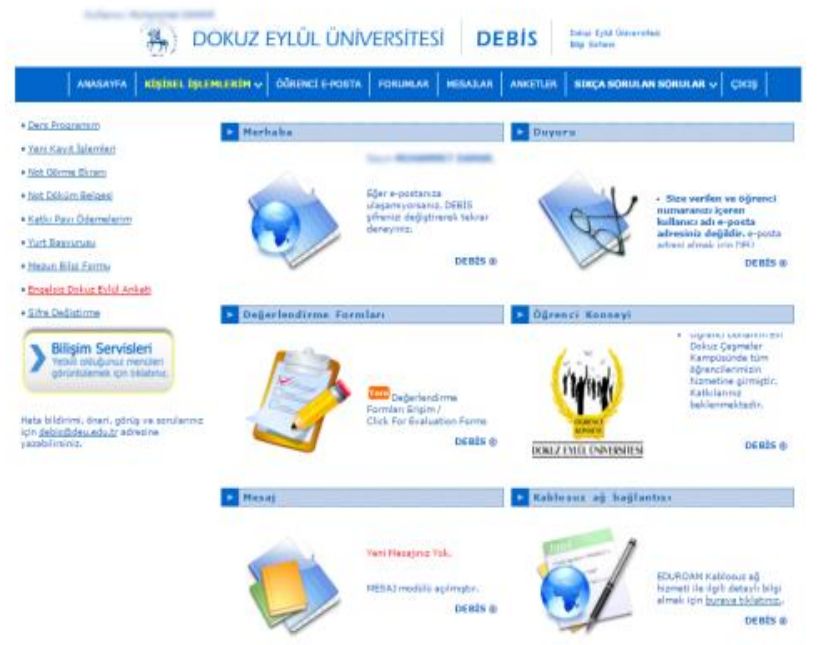

Şekil 2. Debis Görünümü (View of Debis)

Bu noktada deüKariyeriM sistematik bir yaklaşımla ihtiyaçlar doğrultusunda gerçekleştirilen bir kariyer yönetim sistemi olmasının yanında, üniversite bilgi sistemlerine entegre inşa edilmiş bir uygulama olmasıyla üniversite dışından temin edilen yazılımlardan[32] farklılık göstermektedir. Çalışmanın kurum içindeki diğer sistemler ile entegre bir şekilde gerçekleştirilmesi, yetki dağıtımı, güvenlik, verinin tutarlılığı ve tekrarının engellenmesi gibi bir çok noktada fayda sağlamıştır. Yazılımlar yaşayan ürünlerdir, ihtiyaçlar doğrultusunda gelişebilmekte ve yeni görevleri üstlerine alabilmektedirler. Bu noktada gerçekleştirim ekibinin ve teknolojinin tamamen kurum içinde oluşturulması deüKariyeriM yaşam faaliyetlerine kolaylaştırıcı etki yaratacaktır.

\subsection{Mezun Süreçleri (Alumni Processes)}

Mezunlar ile sanayiden gelen iş imkânları, sektörel eğitimler, bölümlerin özel günleri vb. konularda iletişime geçildiği süreçleri kapsar. Şekil 3 üzerindeki formda görüldüğü üzere öğrencilerin iletişim bilgilerinin doğruluğunu kontrol edebilmeleri için bir ekran mevcuttur. Yanlıș bilgiler mezuniyet öncesi bölüm öğrenci işleri ile koordine olunarak sistemden düzeltilebilmektedir. $\mathrm{Bu}$ şekilde öğrencilerin mezuniyet öncesi güncel iletişim bilgisine ulaşılabilmektedir. Ayrıca sistemde verinin tek bir yerde tutulmasının getirdiği avantaj ile veri tekrarından kaçınılmıştır. Bu şekilde entegre geliştirilmiş sistemlerin avantajlı noktalarından verinin tutarlılığı korunmuş olmaktadır.

- Mezun Çıkış Alma Süreci: Mezun bilgi formunun çıktısı sistemden pdf formatında alınabilmektedir. İlgili form üniversite genelinde, öğrencilerin çıkış alma süreçlerinde gerekli belgelerdendir. Mezuniyete hak kazanmış öğrenciler ilgili formu iletişim bilgilerini ve ilgi duydukları meslek bilgilerini doldurarak çıkış evrakları arasında bölüme imzalı teslim etmektedirler. Bu şekilde öğrencilerin mezuniyet öncesi en güncel bilgileri kayıt altına alınmış olmaktadir.

- Mezun İletişim Süreci: Doldurulan form mezun iletişimi için güncel verilerin tutulması
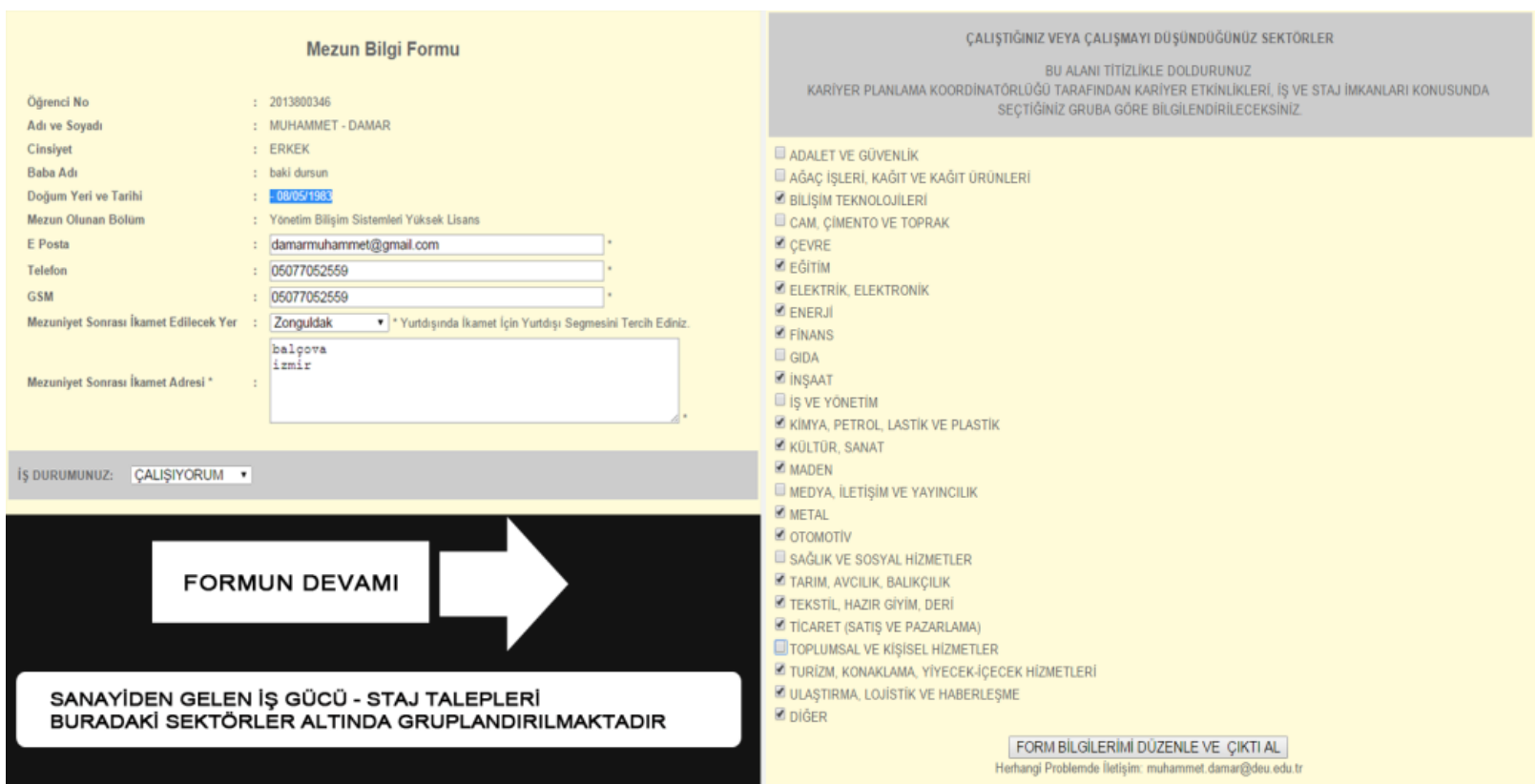

Şekil 3. Mezun Bilgi Formu Ekran Görünümü (Alumni Information Form Screen Display) 
noktasında kritik önemdedir. Bu form sayesinde birim sekreterleri kariyer planlama koordinatörlükleri bölüm, fakülte veya kampüs bazlı mezun öğrenciler ile iletişime geçebilmektedir.

- Sürecin Kazanımları: deüKariyeriM öncesi eski süreç Şekil 4 üzerinde gösterilmiştir. Gerçekleştirilen süreç Dokuz Eylül Üniversitesi Kariyer Planlama Koordinatörlüğü tarafından yürütülmektedir. Süreçte fakültelerden mezun bilgi formları dönemsel olarak toplanmaktadır. $\mathrm{Bu}$ süreçte veri kaybı, kişi, bölüm veya fakülte bazlı mezunlara iletişim zorluğu, maillerin güncelliğinin korunması, kâğıt üzerindeki verinin dijitalleştirilmesi, iletişim kanalının sadece oluşturulacak bir mail grubu aracılığıyla gerçeklemesi gibi güçlükleri mevcuttur.

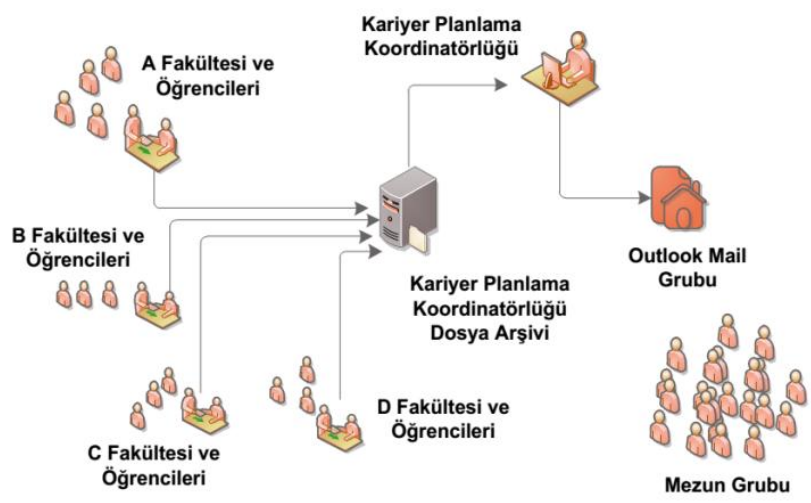

Şekil 4. deuKariyeriM Öncesi Mezun İletişim Süreci (Alumni Communication Process Before deuKariyeriM)

\subsection{Sanayiden Gelen İsgücü Talep Süreçleri (Labor Demand} ProcessFrom The Industry)

Üniversiteler ülkelerin kalkınması ve gelişmesi için nitelikli insan kaynaklarının yetiştirildiği kurumlardır. Bu durumun farkında olan firmalar iş gücü gereksinimlerini kariyer siteleri yanında doğrudan üniversiteler üzerinden gerçekleştirmek isteyebilmektedir. $\mathrm{Bu}$ noktada üniversitelerin firmalardan gelen işgücü taleplerini öğrenim görmekte olan öğrencilere ve mezunlara iletmesi bir problem olarak karşımıza çıkmaktadır. Nitekim deüKariyeriM gerçekleştirim sürecinde bu durum karşımıza bir ihtiyaç olarak çıkmıştır. Bu doğrultuda sanayiden gelen işgücü taleplerinin yönetim süreci Şekil 5 üzerinde görüldüğü şekilde oluşturulmuştur. Oluşturulan sistem sayesinde iş gücü (iş/staj talepleri) talepleri için firmalar kurumsal bir sistem ile, ikili ilişkilere gerek kalmadan taleplerini iletebilmektedir. Firmaların talepleri bir veri tabanında tutulabilmekte bu şekilde başvuruların kabul/red noktasında kontrolü sağlanmış olmaktadır. Sistemin herhangi özel bir çatı gereksinimi olmadan Dokuz Eylül Üniversitesi Bilgi Sistemine entegre bir şekilde çalışabilmesi kullanıcı yetkilendirme konusunda kolaylık sağlamıştır.

\section{4. Üniversite Ögrencileri Ile Illetişim (Communication With College Students)}

Üniversiteler içinde bölüm, fakülte veya enstitüler için öğrencilerine ulaşmak dönem dönem imkânsız hale gelebilmektedir. Aynı durum idari birimler içerisinde gösterebileceğimiz öğrenci işleri daire başkanlığı, dış ilişkiler koordinatörlüğü, farabi kurum koordinatörlüğü vb. birimler için de söz konusudur. Bu durumun en büyük nedeni olarak öğrenciler ile kurum arasında etkin bir iletişim kanalı oluşturamamak gösterilebilir. DEÜ içerisindeki süreçler incelendiğinde; fakülte, enstitü, yüksekokul sekreterlikleri ile kariyer planlama koordinatörlüğüne üzerinden işleyen bir iletişim kanalı oluşturulmuştur. Şekil 6 üzerinde bu süreç gösterilmiştir.

Eğitim faaliyeti süren öğrenci iletişim süreçlerinde kritik parametremiz öğrencilerin en güncel mail adresine erişimdir. DEÜ Öğrencileri, debis sistemini not işlemleri, kayıt yenileme vb. öğrenim faaliyetleri için aktif bir şekilde kullanmaktadır. Fakat öğrenciler çeşitli sebeplerden dolayı dönemsel olarak mail adreslerini değiştirebilmekte ve ilk kayıt oldukları haliyle bırakmamaktadırlar. Bu noktada öğrencilerin istedikleri zaman aktif mail adreslerini değiştirebilecekleri bir ekran oluşturarak en güncel mail bilgisine erişim

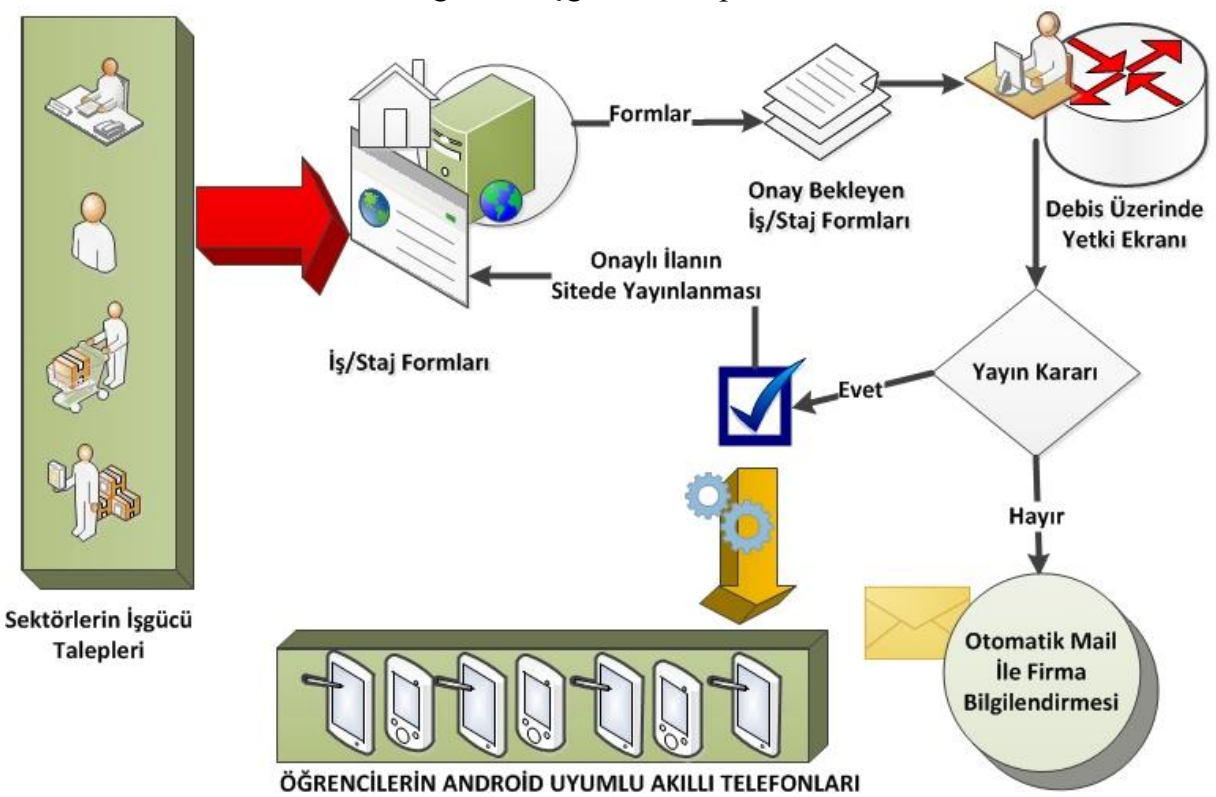

KARIYER YÖNETIM SISTEM ISS/STAJ FORMLARI YÖNETIMI

Sistem Debis'e Entegre Çalışmaktadır

- Personel Sistemi ile Entegre Bir Sistemdir. Bu Sayede istenilen Dokuz Eylül Personeline Kariyer Yönetim Süreçleri İçin Yönetim Yetkisi Verilebilir.

- Tüm Başvurular Kayıt Altına Alınır. Bu Sayede Kayıtlar İle İigili Istatistiklere Ulaşıma İmkanı Mevcuttur.

- Onaylanan Formlar Site ve Mobil Uygulama Üzerinde Anında Yayınlanır.

- Mobil Ve Web Sitesi Üzerinde is Staj Başvurularının íki farklı Platform Üzerinde Yayınlanması İçin Kullanıcılar Özel Bir Çaba Sarfetmez.

- Red Yiyen Firma Otomatik Bilgilendirilir. 
kolaylaştırılmıştır.

$\mathrm{Bu}$ süreçte karşılaşılan bir başka durum bir mail hesabından gönderilen mail sayısının çok fazla irdelenmiştir. $\mathrm{Bu}$ noktada karşımıza çıkan olumsuz durumlardan birisi DEÜ Kariyer Planlama Koordinatörlüğü birimi için etkin, kullanım ve yönetimi kolay, görsellik açısından kullanıcı dostu, mobil teknolojileri destekleyen bir web sayfasına sahip

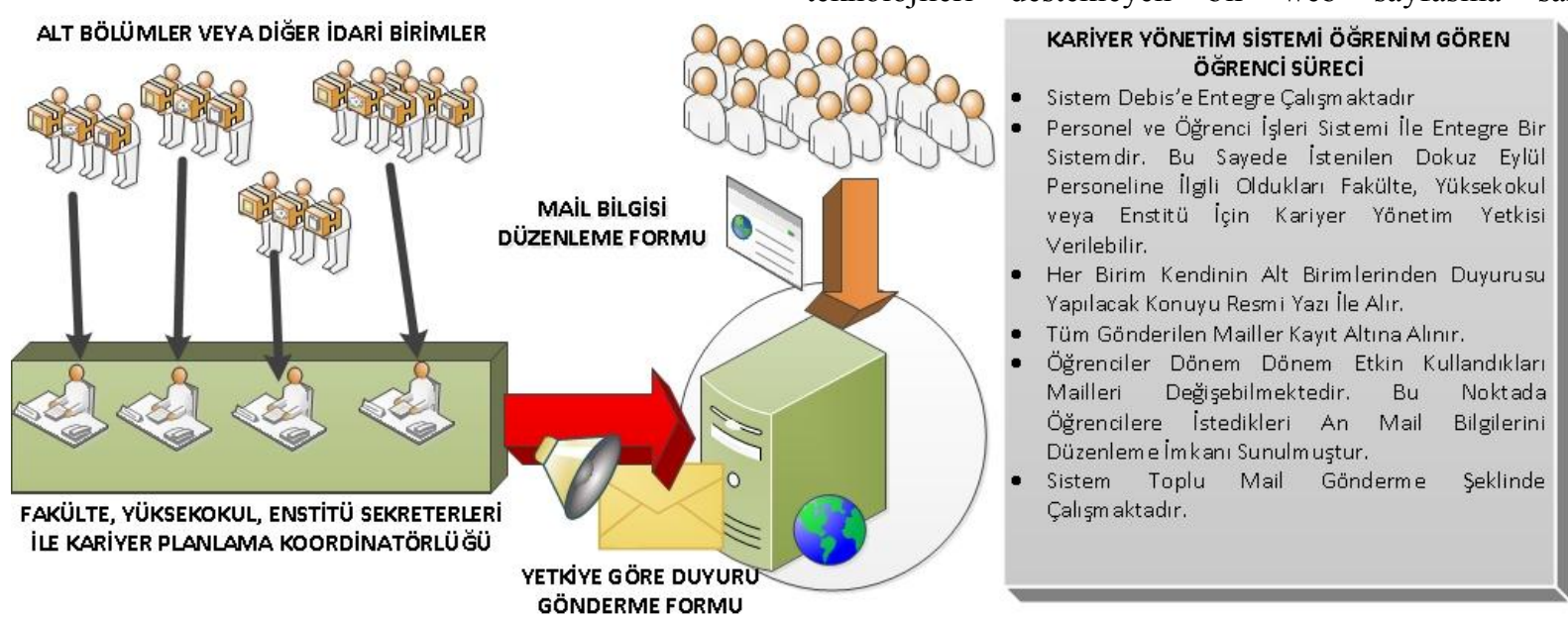

Şekil 6. Eğitim Faaliyeti Süren Öğrenci İletişim Süreci

(Current Student Communication Process)

olmasından dolayı gmail, hotmail, yahoo vb. mail servislerinin spam mail veya saldırı olarak mailleri değerlendirmesi durumudur. $\mathrm{Bu}$ noktada gönderilen mailler bu hususlar dikkate alınarak mail büyük nedeni olarak öğrenciler ile kurum arasında etkin bir iletişim kanalı oluşturamamak gösterilebilir. DEÜ içerisindeki süreçler incelendiğinde; fakülte, enstitü, yüksekokul sekreterlikleri ile kariyer planlama koordinatörlüğüne üzerinden işleyen bir iletişim kanalı oluşturulmuştur. Şekil 6 üzerinde bu süreç gösterilmiştir.

Eğitim faaliyeti süren öğrenci iletişim süreçlerinde kritik parametremiz öğrencilerin en güncel mail adresine erişimdir. DEÜ Öğrencileri, debis sistemini not işlemleri, kayıt yenileme vb. öğrenim faaliyetleri için aktif bir şekilde kullanmaktadır. Fakat öğrenciler çeşitli sebeplerden dolayı dönemsel olarak mail adreslerini değiştirebilmekte ve ilk kayıt oldukları haliyle bırakmamaktadırlar. Bu noktada öğrencilerin istedikleri zaman aktif mail adreslerini değiştirebilecekleri bir ekran oluşturarak en güncel mail bilgisine erişim kolaylaştırılmıştır.

$\mathrm{Bu}$ süreçte karşılaşılan bir başka durum bir mail hesabından gönderilen mail sayısının çok fazla olmasından dolayı gmail, hotmail, yahoo vb. mail servislerinin spam mail veya saldırı maili olarak mailleri değerlendirmesi durumudur. $\mathrm{Bu}$ noktada gönderilen mailler bu hususlar dikkate alınarak mail formatları ayarlanmış ve iki mail arasındaki gönderim süresi için bir gecikme zamanı ilave edilmiştir.

\subsection{Içerik Yönetime Sistemine Sahip Web Sayfası (A Web Site With Content Management System)}

Çalışmaya başlamadan önce, deüKariyeriM süreçlerinin oluşum safhasında, hâlihazırda işleyen süreçler olmadığıdır. Web sayfasına herhangi bir güncelleme veya ekleme yapılacağı zaman ara bir program vasıtasıyla güncelleme kişisel bilgisayarda yapılır, düzenleme sonrasinda web sunucudaki eski dosyalar yeni dosyalar ile değiştirmek şeklinde gerçekleşmektedir. $\mathrm{Bu}$ durumun birçok dezavantajı mevcuttur. Dezavantaj olabilecek durumlar arasında her personelin aynı teknik tasarım veya programlama bilgisine sahip olamayacağ yeniden sunudaki dosyaların oluşturulması gereği, kişiye bağlı sürdürülebilirliği zor bir süreç ile karşı karşıya olunması sayılabilir.

$\mathrm{Bu}$ teşhis sonrası ihtiyaçlar ve personelin bilgi düzeyi göz önüne alınarak web sayfası için yeni bir yapılanmaya gidilmiştir. Bu doğrultuda açık kaynak kod içerik yönetim sistemleri karşımıza çözüm olarak çıkmıştır.

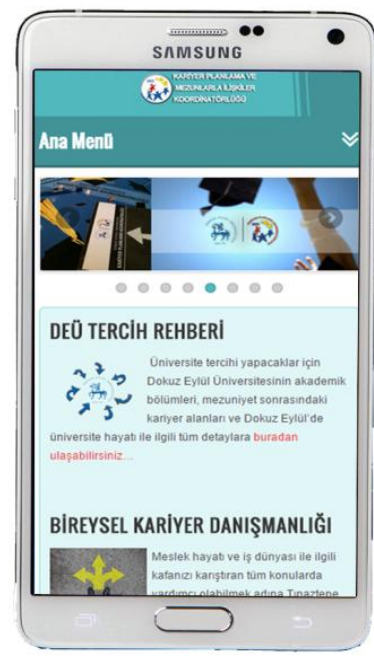

Şekil 7. Websitenin Mobil Cihazda Görünümü (Website View in Mobile Device) 
Web içerik yönetim sistemi, web içerik bileşenlerinin yönetim işlemlerinin gerçekleştirildiği web tabanlı yazılımlardır[33]. Açık kaynak kodlu web içerik yönetim sistemi yazılımları arasında wordpress, joomla, drupal vb. yazılımlar sayılabilir. Özdaş Kamuda Açık Kaynak Kodlu Yazılım Kullanımı Çalışma Raporu'nda, açık kaynak kodlu yazılımların kullanılmasını kamu için faydalı bulmaktadir[34].

Süreçte kullanım kolaylığı ve kolay ara yüzünün yanında, kurum içi çeşitli birim web sayfalarında tecrübe edilmesinden ötürü, joomla web içerik yönetim sistemi ilgili birime çözüm olarak sunulmuştur. Kullanıcıların web sitesinden daha iyi faydalanabilmeleri için menü hiyerarşisi yeniden kurgulanmış; aday, mezun ve öğrenim görmekte olan öğrenciler olmak üzere bir sınıflamaya gidilmiştir. Ayrıca duyuru ve etkinliklerin birim için öneminden ötürü bu tür menü elemanlarının site içerisinde görünürlük ve farkındalığını artırmak adına tasarım üzerinde değişikliklere gidilmiştir.

Şekil 7 üzerinde görüldüğü gibi, mobil tasarım sayesinde öğrenciler kariyer merkezi ile ilgili iş duyurusu, staj duyurusu özetler web sayfası üzerinde yayınlanan tüm bilgiye kolayca ve kullandıkları mobil cihaza uygun ara yüz ile erişebilmektedir.

\subsection{Yeni Mobil Kariyer Süreci (New Mobile Career Processes)}

Şekil 5 üzerinde yeni sürecin çalışma şekliyle ilgili sistematik bir gösterim söz konusudur. Şekil üzerindeki süreç, sadece firmalardan gelen işgücü taleplerin yönetimi gibi görünse de sürecin mobil ayağında sadece işgücü talepleri yoktur. Duyuru, haber etkinlik gibi bilgilerin girişi yetkili tarafından Debis üzerinden yapılabilmekte ve girilen bilgi mobil uygulama ekranına düşmektedir. Şekil 8 üzerinde mobil uygulamadan görünüm gösterilmektedir.
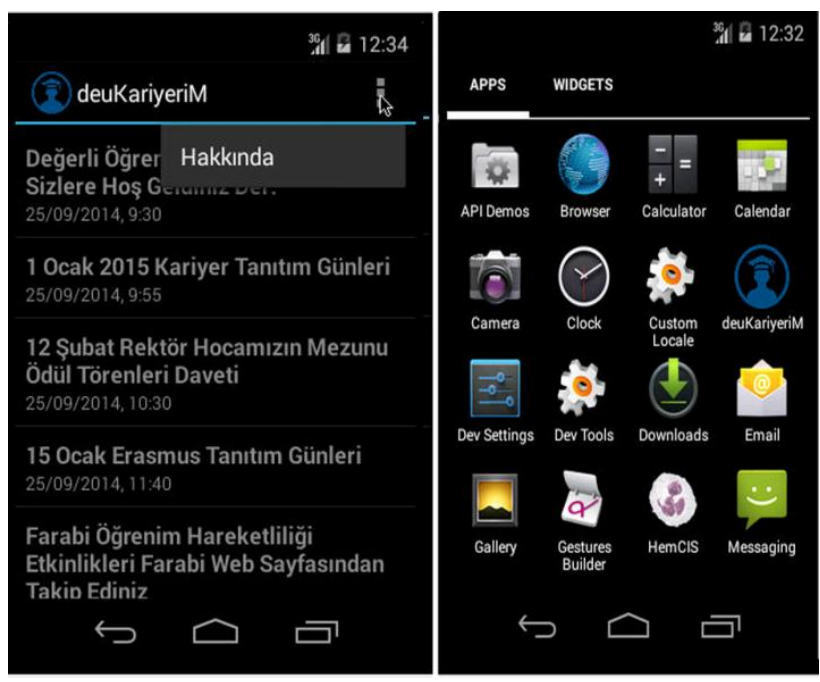

Şekil 8. deüKariyeriM Mobil Uygulamasından Görünüm (deüKariyeriM Mobil Application View)

Mobil uygulama yönetim yetkisi sadece kariyer planlama koordinatörlüğüne verilmiştir. Fakat projenin DEÜ içerisindeki sistemler ile entegre bir şekilde geliştirilmesinin olumlu etkisi olarak ilerleyen süreçlerde fakülte, enstitü veya yüksekokul sekreterlerine de verilebilir. Uygulama Google Play Store üzerinden ücretsiz bir şekilde indirilebilmektedir. Projede kullanılan ve Şekil 9 üzerinde kurulan süreç sayesinde uygulama istenildiği şekilde çoğaltılabilir, ihtiyaçlar doğrultusunda şekillenebilen bir yapıya sahiptir.

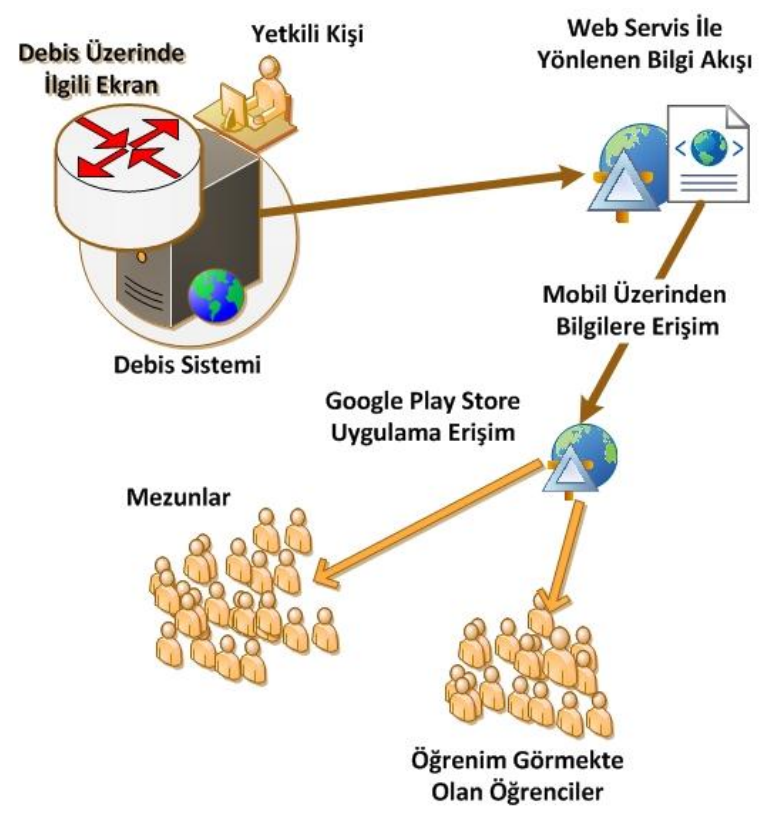

Şekil 9. Mobil Uygulama İşleyişi (Mobile Application Operation)

Mobil uygulama web servis vasitasıyla Debis sisteminden çekilen veriyi kullanıcılarına sunmaktadır. Uygulama içerisinde ilgili etkinlik, bildirim veya duyuru istenilen gün ve duyuruda kullanıcısını uyaracak şekilde oluşturulmuştur. Uygulama web servisten veriyi çekerek etkinlik, duyuru ve bildirimler noktasında kendini güncellemektedir. Bu şekilde kullanıcıların herhangi özel bir şey yapmadan süreç hakkında bilgilendirilmesi sağlanmış olmaktadır.

Kurulan süreç içerisinde, kullanılan veri tabanı tabloların çeşitlendirilmesi, ihtiyaçlar doğrultusunda optimize edilerek web servis üzerinde güncelleme yapılması ile mobil uygulama çoğaltılabilir. Örneğin sadece fen fakültesi duyuruları, sadece enstitülerin duyuruları, sadece etkinlik haberleri şeklinde mobil uygulama çeşitlenebilir. Bunu için debis üzerinde ek uygulamalar oluşturmak, yeni tablolar oluşturmak ve servis optimizasyonu yapmak, java android uygulama tarafında verinin çekileceği alanı değiştirmek yeterli olacaktır. $\mathrm{Bu}$ yapı sayesinde fonksiyonel mobil uygulamaları gerçekleştirilebilir. 


\section{SONUÇ VE DEĞERLENDİRME (CONCLUSION AND EVALUATION)}

Yükseköğretim kurumları, nitelikli insan kaynaklarının yetiştirildiği kurumlardır. $\mathrm{Bu}$ bağlamda mezun ve öğrenim görmekte olan öğrencilerin kariyer süreçlerinin etkinleştirilmesi önemlidir. Kariyer hizmetlerinin sunulması gün geçtikçe üniversiteler için kütüphane, laboratuar vb. hizmetler gibi temel zorunluluk haline gelmektedir. $\mathrm{Bu}$ faaliyetler üniversitelerde içinde kariyer planlama koordinatörlükleri veya mezun ofisleri gibi çeşitli birimler üzerinden sürdürülmektedir. Dokuz Eylül Üniversitesi'nde bu faaliyetler DEÜ Kariyer Planlama Koordinatörlügü tarafından sürdürülmektedir ve bu faaliyetler sırasında mezun ve öğrenim faaliyeti devam eden ögrenciler ile iletişime geçmek bir problem olarak ortaya çıkmıştır. Bu noktada geliştirilen deuKariyeriM uygulaması, sistem yaklaşımı ile ihtiyaçlar ve yapılan analizler doğrultusunda projelendirilmiştir.

Yapılan literatür çalışmasının sonucu, üniversitelerdeki kariyer yönetim süreçlerinin önemini ortaya koymuştur. Çalışma, üniversite birimleri, mezunlar ve öğrenim gören öğrencilerin kariyer süreçlerini sistematik bir yaklaşım ile ele alarak ihtiyaçlar doğrultusunda bir uygulama ve süreçleri ortaya koymuştur. Literatür incelendiğinde gerçekleştirilen bu çalışmanın üniversite kariyer yönetimi süreçlerini bilgi sistemleri ile yönetimi, süreç oluşturması ve süreçlerin oluşturulmasından uygulamaya geçerken ki deneyim ve tecrübenin aktarılması noktasında öncü çalışmalardan olduğu görülmektedir.

Oluşturulan süreçler, öğrenciler ile kariyer planlama koordinatörlüğü ve fakülte, enstitü ve yüksekokul sekreterliklerinin etkileşimini kolaylaştıran bir çalışmadır. Öğrenciler ile iletişim problemi sistematik bir şekilde ele alınmış, etkileşim için mobil teknoloji, mail, gsm vb. bilgilerine erişim kolaylıkları sunulmuştur.

Süreçlerde DEÜ'nin kendi iç dinamikleri gözetilerek bir sistem kurulmuş olması ve oluşturulan süreçlerin aktarılması diğer üniversiteler için örnek teşkil edebilir. Gerçekleştirilen sistemin öğrenci işleri otomasyonu ve personel otomasyonu gibi üniversite içindeki diğer sistemler ile entegre çalışabilmesi bilginin yönetimi ve güncelliği adına önem taşımaktadır. Çalışmada kurum içi sistemler ile entegre uygulamanın işlevsellik ve etkinliği artırdığı görüldüğü gibi projeyi ihtiyaçlar doğrultusunda şekillendirmede diğer projelerden beslenildiği görülmüştür.

\section{KAYNAKLAR (REFERENCES)}

[1] Güçlü N., Karadăg N., "Türkiye ve AB Ülkeleri Yükseköğretim Kurumlarının Kuruluş Amaçları Doğrultusunda Genel Amaç, Vizyon ve Misyonlarının Karşılaştırılması", Uluslararası Yükseköğretim Kongresi: Yeni Yönelişler ve Sorunlar (UYK-2011) 27-29 Mayıs 2011, İstanbul; 1. Cilt / Bölüm VII / Sayfa 667-675, (2011)

[2] İnternet: Üniversitenin Amaçları, http://www.fatih.edu.tr/?amaclar 30.11.2014
[3] Pekkaya M., Çolak N., "Üniversite Öğrencilerinin Meslek Seçimini Etkileyen Faktörlerin Önem Derecelerinin Ahp İle Belirlenmesi", The Journal of Academic Social Science Studies International Journal of Social Science Volume 6 Issue 2, p. 797-818,(2013)

[4] Demircioğlu Ö., "Gazi Üniversitesi Merkez Kütüphanesi: Bilgiyi Hayata Dönüștüren Kütüphane", Bilgi Dünyası 2007, 8(1): 167-173, (2007)

[5] İnternet: Sabanc1 Üniversitesi Mezun Ofisi, http://www.sabanciuniv.edu/tr/mezunlar/mezunlar-ofisi 30.11.2014

[6] İnternet: Boğaziçi Üniversitesi Mezun Ofisi, https://mezun.boun.edu.tr/ 30.11.2014

[7] İnternet: Boğaziçi Üniversitesi Mezun Ofisi, http://www.kariyermerkezi.boun.edu.tr/ 30.11.2014

[8] İnternet: Boğaziçi Üniversitesi Vakfi, http://www.buvak.org.tr/ 30.11.2014

[9] İnternet: Harward Üniversitesi Mezun Sitesi, http://alumni.harvard.edu/ 30.11.2014

[10] Ekinci E.C., Burgaz B.,"Hacettepe Üniversitesi Öğrencilerinin Bazı Akademik Hizmetlere İlișkin Beklenti ve Memnuniyet Düzeyleri",Hacettepe Üniversitesi Eğitim Fakültesi Dergisi (H. U. Journal Of Education) 33: 120-134, (2007)

[11] Yunus Ş.İ., Zoraloğlu R., Şahin N., "Üniversite Öğrencilerinin Eğitimsel Amaçlarına Ulaşmalarını Etkileyen Etkenlere İlişkin Görüşleri", Firat İnönü Üniversitesi Eğitim Fakültesi Dergisi Ağustos 2010/ Cilt. 11, Say1. 2, Ss. 133-154, (2010)

[12] T Karataş, A. ve Gizir, C. A., "Üniversite öğrencilerinin psikolojik danışma gereksinimlerinin çeşitli değişkenler açısından incelenmesi", Hacettepe Üniversitesi Eğitim Fakültesi Dergisi,28(3), 250-265. (2013)

[13] Perine, M. ve Lisle, J., "Effects Of Syllabus Offer Of Help, Student Age And Class Size On College Students' Willingness To Seek Support From Faculty" Psychology And Behavioral Sciences Collection, 64(1), 41-52. (1995)

[14] İnternet: The University Of Adelaide University Austalia Alumni Relations Strategic Plan $2007 \quad-\quad 2011$, http://www.alumni.adelaide.edu.au/s/923/images/FileLibrary/a2a36ed1 e992-432a-8582-9ea48f00efd2.pdf 01.12.2014

[15] İnternet: Association Of Yale Alumni Strategic Plan 2012-2017, http://www.aya.yale.edu/content/strategic-plan 01.12.2014

[16] İnternet: Cal Alumni Association Strategic Plan For 2013-2017, 01.12.2014; $\quad$ http://alumni.berkeley.edu/sites/default/files/20132017\%20CAA\%20Strategic\%20Plan_1.pdf 01.12.2014

[17] Akoğlan Kozak M.A.,Dalkıranoğlu T., "Mezun Öğrencilerin Kariyer Algılamaları: Anadolu Üniversitesi Örneği", Anadolu Üniversitesi Sosyal Bilimler Dergisi, Cilt 13 Sayı:1,(2013)

[18] Topkaya N., Meydan B., "Üniversite Öğrencilerinin Problem Yaşadıkları Alanlar, Yardım Kaynakları ve Psikolojik Yardım Alma Niyetleri", Trakya Üniversitesi Eğitim Fakültesi Dergisi 2013, Cilt 3, Sayı 1, 25-37, (2013)

[19]Seçer B., Çınar E., Bireycilik ve Yeni Kariyer Yönelimleri, Yönetim Ve Ekonomi Dergisi, Y11:2011 Cilt:18 Say1:2 Celal Bayar Üniversitesi, (2011) 
[20] Güler B.K., Emeç H.,"Yaşam Memnuniyeti ve Akademik Başarıda İyimserlik Etkisi", D.E.Ü.İ.İ.B.F. Dergisi Cilt:21 Sayı:2, Yı1:2006, Ss:129-149, (2006)

[21]Korukoğlu A., "Üniversite Öğrencilerinin Eğitimden Beklentileri Ege Üniversitesi İ.İ.B.F. Örneği", Süleyman Demirel Üniversitesi İktisadi Ve İdari Bilimler Fakültesi Y.2003,C8, S.L S.79-89. (2003)

[22] Yıldırım K, "Pisa 2006 Verilerine Göre Türkiye'de Eğitimin Kalitesini Belirleyen Temel Faktörler", Türk Eğitim Bilimleri Dergisi Bahar 2012, 10(2), 229-255,(2012)

[23]Erdoğmuş, N.,"Kariyer Geliştirme, Kuram ve Uygulama", Nobel Yayın Dağıtım, Ankara. (2003)

[24] TÜZ M.V, "Kariyer Planlamasında Yeni Yaklașımlar", U.Ü.FenEdebiyat Fakültesi Sosyal Bilimler Dergisi, 4 (4), 2003/1, s. 171. (2003)

[25] Değirmencioğlu S.M., “Türkiye'de Yüksek Öğretim Mezunları ve Eğitimde Fırsat Eşitliğii”, Toplum ve Demokrasi Dergisi, 2 (3), MayısAğustos,47-66.(2008)

[26] McAlexander J.H.,Koenig H.F., Schouten J.W, "Building a University Brand Community: The Long-Term Impact of Shared Experiences", Journal of Marketing for Higher Education, 14 (2),61-79. (2008)

[27] Gedikoğlu T., "Avrupa Birliği Sürecinde Türk Eğitim Sistemi: Sorunlar ve Çözüm Önerileri”, Mersin Üniversitesi Eğitim Fakültesi Dergisi", 1 (1), Haziran, 66-80.(2005)
[28] İnternet: ODTÜ Mezunları Derneği, http://odtu-mebiva.org.tr/ 09.03 .2015

[29] İnternet: İTÜ Mezunlar Derneği, http://www.ituvakif.org.tr/ 09.03 .2015

[30] İnternet: Yıldız Teknik Üniversitesi Öğrenci Bilgi Sistemi, http://www.yildiz.edu.tr/orbis/ 09.03.2015

[31] İnternet: Sakarya Üniversitesi Bilgi Sistemi, https://sabis.sakarya.edu.tr/ 09.03.2015

[31] İnternet: İzmir Yüksek Teknoloji Enstitüsü Öğrenci İşleri Bilgi Sistemi, https://obs.iyte.edu.tr/ 09.03.2015

[32] İnternet: Yıldız Teknik Üniversitesi Kariyer Geliştirme Merkezi, http://www.orkam.yildiz.edu.tr/ 09.03.2015

[33] Tekerek A., Bay F.Ö., "Web İçerik Yönetim Sistemi Tasarımı ve Gerçekleştirilmesi", Politeknik Dergisi, 12 ( 2), 85-91.(2009)

[34] Özdaş R.M., "Kamuda Açık Kaynak Kodlu Yazılım Kullanımı", TC. Kalkınma Bakanlığı Bilgi Toplumu Dairesi, Çalıșma Raporu 4.(2012) 